\title{
Nos bastidores do poder: \\ Política e relações familiares no Piauí do século XIX
}

\author{
In the background of power: \\ Political power and family relationships in Piauí in the XIX century
}

\section{Marcelo de Sousa Neto}

Resumo: A organização política no Piauí do século XIX constituiu-se enquanto um bem familiar que deixou profundas marcas na organização e cotidiano político local e na composição dos grupos dirigentes de então. Discutir os espaços de atuação e enfrentamento político no período em foco é, em seu sentido amplo, discutir a história das famílias e das redes de relações constituídas, espaços estes nos quais a relação entre família e poder representaram uma constante. Dessa forma, o presente estudo propõe debruçar-se um pouco mais sobre a história das famílias piauienses e suas práticas, seguindo as trilhas deixadas por Tanya Brandão (1995 e I999), Moysés Castelo Branco Filho (I982 e I983), Pedro Vilarinho Castelo Branco (2005), Ana Regina Rêgo (200I) e Sousa Neto (2013), como arcabouço teórico-metodológico para pensar as relações entre família e poder político na Província do Piauí. Justifica-se o estudo ao reconhecemos, como destaca Maria Beatriz Nizza da Silva (I998), uma produção crescente sobre o tema família, mas ainda carente de estudos sobre capitanias periféricas da empresa colonial portuguesa. Verificou-se que no Piauí a família assumiu contornos particulares e multifacetados que deixaram marcas profundas em sua organização sócio-política, na qual seus membros, por meio de uma estreita rede de alianças, assumiram espaços de poder político e econômico que permitiram sua atuação nas mais diversas esferas sociais.

Palavras-chave: Família; poder; Piauí.

\footnotetext{
* Professor Adjunto da Universidade Estadual do Piauí. Doutor em História pela Universidade Federal do Pernambuco.
} 
Abstract: The political organization in Piauí in the XIX century is constituted as a family heritage that left deep marks in the organization and local political daily as well as in the composition of the leader groups of that moment. Discuss the spaces of action and political coping during that period is, in its large sense, discuss the history of families and of the constituted relationships, spaces in which the relationship between family and power represented a constant. In this way, the present study intends to look into history of Piauiense families and their practices, following the trails pointed by Tanya Brandão (I995 and 1999), Moysés Castelo Branco Filho (1982 and 1983), Pedro Vilarinho Castelo Branco (2005), Ana Regina Rêgo (200I) and Sousa Neto (20I3), as theoretical and methodology outline to think the relationships between family and political power in the Piauí Province. This study is justified because we recognize, as Maria Beatriz Nizza da Silva (1998) points out, an increasing production about the theme family, but yet lacking in studies about peripheral captaincies of the Portuguese colonial enterprise. It was found that in Piauí the family took particular and multifaceted contours that left significant marks in its social and political organization, in what its members, by means of a close network of alliances, took spaces of political and economic power that permited their action on several social spheres.

Keywords: Family; power; Piauí.

\section{Introdução}

A organização política no Piauí do século XIX constituiu-se enquanto um bem familiar que deixou profundas marcas na organização e cotidiano político local e na composição dos grupos dirigentes de então, constituídos a partir de redes familiares que se alicerçavam "moldados no parentesco, na solidariedade mútua e no manejo com o poder" (BRANDÃO, I995, p.275). Assim, discutir os espaços de atuação e enfrentamento político no período em foco é, em seu sentido amplo, discutir a história das famílias e das redes de relações constituídas, espaços estes nos quais a relação entre família e poder representaram uma constante (BRANDÃO, 1995).

A família, como campo de investigação histórica, representa objeto constante nas produções recentes e se relaciona a vários outros temas analisados pela historiografia, a exemplo de pesquisas sobre a mulher, a infância, a educação, o cotidiano, as sensibilidades, o indivíduo, o amor, o casamento, etc. No entanto, mesmo estando presente de maneira 
significativa em uma variedade de pesquisas no âmbito da história social, a individualização da família enquanto objeto de estudo remonta apenas a meados do século $\mathrm{XX}$.

Assim, tomando como inspiração as provocações de Capistrano de Abreu (1976), que já alertava sobre a importância do estudo da família para a história do Brasil, este escrito propõe debruçar-se um pouco mais sobre a história das famílias piauienses e suas práticas, como forma de delimitar seu estudo, seguindo as trilhas deixadas por Tanya Brandão (I995, I999, 2002, 2004, 2006) $)^{\mathrm{I}}$, que frisa em seus escritos a carência e as dificuldades de pesquisas sobre a organização familiar piauiense.

A esse respeito, reconhecemos e parabenizamos uma produção crescente sobre o tema família, mas que ainda há muito a ser pesquisado acerca da história e organização da família brasileira, pois, mesmo possuindo valorosos trabalhos, sobretudo ligados à família colonial, muito ainda falta a ser pesquisado, especialmente com estudos sobre capitanias periféricas da empresa colonial portuguesa (SILVA, 1998).

Quanto à historiografia piauiense, os estudos sobre família também não representam tema deserto. Destacam-se, nessa perspectiva, os estudos pioneiros de Moysés Castelo Branco Filho (I982 e 1983), e mais recentes, os escritos de Tanya Maria Pires Brandão (I995, 200I e 2004), Pedro Vilarinho Castelo Branco (2005) e Ana Regina Rêgo (200I) ${ }^{2}$. No entanto, considera-se lacunares os estudos sobre as estratégias de poder das famílias da elite política e econômica na Província ${ }^{3}$, nos quais a temática família aparece diluída em abordagens e descrições mais gerais ${ }^{4}$ ou ainda em obras de genealogia ${ }^{5}$.

No Piauí, a família patriarcal, entendida aqui como uma família de contornos particulares e multifacetados, irredutível a formas pré-determinadas, deixou marcas muito

\footnotetext{
${ }^{\text {I }}$ Ao se localizar a importância da família e suas relações de poder para a construção do objeto de pesquisa deste estudo, estes escritos assumem maior importância ao instante que localizam o papel da família nas relações de poder no Piauí, tomados como referencial capaz de localizar o espaço familiar em que se insere Padre Marcos, discutindo como estas relações atuaram na conquista e manutenção da hegemonia do poder político, por entenderem que o Piauí, como grande parte do país, alicerçou suas relações político-econômicas também a partir da estrutura familiar, na qual a supremacia política consolidou-se quando seus membros passaram a ter a posse da terra e a ocupar os cargos da burocracia estatal.

${ }^{2}$ Apesar de não ser o centro da discussão de sua pesquisa, Rêgo dedica boa parte de suas análises a relação entre família e política no Piauí. Ao que se refere à estrutura familiar piauiense e sua história, os escritos de Brandão ganham capital importância na presente pesquisa pela aproximação de recortes e por também discutir as redes familiares em que se inseriu Padre Marcos.

${ }^{3}$ Apesar das análises de Brandão (1995), reportarem-se até primeiros anos da década de I830, o cerne de sua discussão volta-se período colonial.

${ }^{4}$ São exemplos destas obras: NUNES, 1975; COSTA, I974; CHAVES, I998; ALENCASTRE, 2005; NEVES, I974; NEVES, I997; SANTANA, I995; QUEIROZ, 1994, e TITO FILHO, I973. Esta última obra corresponde a uma republicação comentada, ampliada e acrescida de escritos inéditos de: SOUSA, Esmaragdo de Freitas. O Visconde da Parnaíba. Rio de Janeiro: Ed. Jornal do Comércio, I947; obra a qual acrescenta estudos sobre Manuel Clementino e Padre Marcos.

${ }^{5}$ Por exemplos, podemos apontar CARVALHO, I988 e ARAÚJO COSTA, 1999.
} 
profundas na organização sócio-política da Província. Neste escrito, o estudo da família enquanto instituição ganha espaço privilegiado quando se observa a estreita relação entre família e poder na Colônia e, posteriormente, na Província, na qual seus membros por meio de uma estreita rede de alianças, assumem espaços de poder político e econômico que permitiram sua atuação nas mais diversas esferas sociais.

Nesse sentido, entende-se a família piauiense como um corpo em constante movimento, desenraizado, portador de formas diversas, que não se reduz a conceitos estáticos, mas com algumas características identificáveis pelas atuações de seus membros. Assim, a imagem que ora se apresenta sobre a família piauiense representa um esforço de aproximação com algumas concepções de famílias que não se deixam prender pelo tempo ou espaços da pesquisa, mas que envolvem e instiga o presente, convidando-o a mergulhar nas marcas que elas cravaram na sociedade contemporânea.

\section{Entre Parentes: redes familiares, Estado e patrimônio no Piauí do século XIX}

No Brasil, a formação das famílias constituiu-se em um espaço permeado por disputas. Segundo Luiz Pinto (1980), essas disputas surgem da importância e da forma organizacional familiar, frente à fraqueza da organização do Estado, fenômeno presente em todo o Brasil colonial, sobretudo nas regiões não-exportadoras, estendendo-se por boa parte no Império e deixando ainda reflexos no início da República.

Essas disputas também se fizeram presentes no Piauí que, como em outras regiões periféricas da empresa colonial portuguesa, buscava impor seus interesses locais em relação à influência das regiões exportadoras (CARDOSO, 1996). Se essas disputas não se fizeram sentir pelo derramamento de sangue (PINTO, I980 $)^{6}$, ficaram marcadas por disputas econômicas e políticas, cujos grupos de origem familiar comum impuseram-se como elite dirigente.

Diferente de ser caracterizada pelo sangue derramado, provocado pelas tensões e disputas, caracterizou-se pela mistura desse sangue via matrimônio.

Em geral, a historiografia apresenta a relação entre Estado e família a partir da ideia de distanciamento, da dicotomia entre as duas esferas, circunscrevendo o primeiro na esfera pública e a segunda na esfera privada. No Brasil, entretanto, essa separação não era tão visível assim, pois, os espaços públicos e privados muitas vezes se confundiam (NOVAIS, 1997), relação importante durante o Império, no qual o poder do Estado era

\footnotetext{
${ }^{6}$ As lutas entre famílias que resultaram em derramamento de sangue foram uma constante durante todo o período colonial, deixando também suas marcas durante Império.
} 
impregnado por relações familiares (MARIANO, 2005), onde, geralmente, eram feitas as alianças e de onde partiam as decisões que marcariam a vida pública.

Essas famílias, que muitas vezes se confundiam com o Estado, constituíram-se em instituição central da vida social, política e econômica de boa parte do Brasil. Sociedades nas quais a formação do extrato de elite deu-se pela utilização de mecanismos que propiciaram a estes grupos legitimarem e ampliarem seu prestígio e poder. Entre eles, a posse da terra e o engajamento no aparelho burocrático do Estado, que aliado com uma "linhagem de prestígio", conferia o direito ao domínio local (LEWIN, I993), fenômeno que também se fez presente no Piauí.

A diferenciação dessas famílias inicia-se a partir da ocupação e da conquista do território, montado como empreendimentos militares familiares, esquadrinhando o desenho da base política da Capitania, cuja relativa autonomia local, resultante da distância em relação à autoridade da Coroa, concorreu para a conquista de prestígio e poder das famílias mais abastardas. Nesse período, o casamento surge como mecanismo utilizado pelas famílias para se aglutinarem, ampliando os laços econômicos, políticos e de solidariedade entre si. Entretanto, já no século XIX, outro mecanismo de aliança entrava em cena, os partidos políticos ${ }^{7}$, que refletiam, mesmo com distorções, os arranjos familiares da Província, no qual se destacam dois poderosos núcleos familiares, um no Centro-Sul da Província, liderados pelos Sousa Martins, mais afeitos ao Partido Conservador e outro núcleo ao Norte, mais Liberais, capitaneados pelos Castelo Branco.

Nesse sentido, entende-se que a melhor maneira de compreender os arranjos e alianças políticas na Província, resultam em promover a investigação dos laços de parentesco, mecanismo pelo qual as redes familiares vão se incorporando à estrutura política (KUZNESOF, $1988 / 89)^{8}$.

Assim, mais uma vez justifica-se a relevância de se tentar compreender o papel das relações de parentesco na organização e distribuição de poder no Piauí, que lança suas bases ainda no final do século XVII, tendo continuidade na vida política durante o Império. Exemplo do que se afirma, pode ser ilustrado com a figura Manuel de Sousa Martins, herdeiro das primeiras famílias de elite a reocupar o Piauí, assumiu funções na

\footnotetext{
${ }^{7}$ Sobre o engajamento familiar nos partidos políticos ver: MARIANO, 2005; RÊGO, 200I e BRANDÃO, 2004.

${ }^{8}$ Em estudo sobre o impacto causado pela família sobre o desenvolvimento econômico e político em São Paulo dos séculos XVI ao XIX, a autora observa que por meio da estrutura de parentesco e da família as redes informais da política passaram a se fixar e ser mantidas no poder. Essa mesma condição é observada por BRANDÃO, I995, no que se refere à sociedade piauiense dos séculos XVII ao XIX. Lembre-se ainda que Cf. ALENCASTRO, Luiz Felipe. Modelos da História e da historiografia imperial. In: NOVAIS, I997, os modos de vida do Império brasileiro tiveram por fundamento a continuidade dos modos de vida herdados da América portuguesa.
} 
administração pública ainda em I804, como militar. Em I82I assume o cargo de VicePresidente da Junta Governativa e, em I843, ainda se encontrava no poder, enquanto Presidente da Província9.

Esse mesmo exemplo serve para ilustrar que as posições tomadas pelos líderes da política local se alicerçavam mais em seus interesses privados e familiares que em suas convicções políticas ou partidárias, observado com a adesão de Sousa Martins à causa da Independência por ter tido seus interesses contrariados na eleição para a Junta Governativa de I822, da qual saiu derrotado. A esse respeito Abdias Neves é bastante esclarecedor. Segundo ele,

o Brigadeiro Manuel de Sousa Martins, que tomara à frente da conspiração, não por patriotismo, nem por amor à independência, mas por despeito por ser vencido nas eleições de 7 de abril de I822, não quis que outro tivesse a glória da proclamação. Compreendeu que não havia mais perigo em aderir ao movimento. Tratou, então, de reunir com urgência os conjurados, que, ao cair da noite 23 de janeiro, foram, um a um, chegando à sua casa (NEVES, I974, p. 84).

Como ainda ressalta Pinto (I980), a força da família, enquanto instância de poder, fezse maior nos locais em que a presença do Estado apresentou-se de forma limitada, no caso em análise, o Piauí colonial, que tinha no grupo familiar a base de sua estrutura de poder, mantendo-a ao longo da primeira metade do século XIX (BRANDÃO, I995). Assim, a família como unidade básica, toma para si boa parte do controle social, inclusive o seu caráter político e jurídico (PINTO, I980 $)^{\mathrm{IO}}$, elementos decisivos na estrutura administrativa local.

Essa estrutura de poder de base familiar somente passou a sofrer desgaste a partir de meados do XIX, quando o pater familias torna-se um arquétipo em decadência ao instante que "novos canais de mobilidade social tinham sido abertos no Brasil, pelo menos para os homens" (LEWIN, I993, p. I73). Entre esses canais, pode-se exemplificar com a expansão

\footnotetext{
${ }^{9}$ A relação de Sousa Martins com a administração pública piauiense remonta a I804, quando ingressa nas forças militares, reformando-se em I820 no posto de Brigadeiro. Foi ainda Comandante das Armas no Piauí durante o ano de I822. No ano de I82I ganha maior visibilidade no cenário político piauiense, quando assume o cargo de Vice-Presidente da Junta Governativa do Piauí (26/10/182I à 07/04/1822). Posteriormente, após ter proclamando a adesão de Oeiras à Independência do Brasil (24/oI/I823), assume a Presidência da Junta Governativa de I823 e mantêm-se no poder, com raros e rápidos interstícios, até 30/12/I843.

${ }^{\text {Io }}$ Segundo o autor, a comunidade de 'sangue' precede a comunidade territorial, na qual a família surge como um "pequeno Estado", assumindo inclusive seu caráter jurídico de promover a justiça, e na ausência de um poder suprafamilial, a vingança privada surge como forma normal e permanente de repressão e defesa do grupo familiar.
} 
das oportunidades na educação, pois, "com a fundação das faculdades de direito e de medicina, na década de I820, os filhos de fazendeiros adquiriram as qualificações formais e o apetite por careiras profissionais que os libertariam da terra e afrouxariam consideravelmente os laços do controle patriarcal" (LEWIN, I993, p. I73).

Os efeitos desses novos canais de mobilidade social somente se fizeram sentir no Piauí apenas no século XIX, canais esses que Padre Marcos de Araújo Costa, pertencente aos grupos familiares do Centro-Sul, teve significativa participação ao preparar estudantes para essas faculdades e para os cargos burocráticos criados no período.

No Piauí, as fazendas constituíram-se em núcleos efetivos de povoamento, produzindo e consumindo bens e produtos, bem como socializando novos membros em seus valores e normas sociais. Nessas, a endogamia entre as famílias de elite constituiu-se em elemento de fortalecimento político e econômico, preservado através da seleção dos cônjuges (BRANDÃO, 1995). A família era, então, tomada como um instrumento de controle social. Para ela convergiam a vida econômica, social e política. Essa condição, por vezes, a colocava em oposição ao Estado, por ter assumido uma série de suas funções sociais. No entanto, ao tempo em que os grupos familiares começaram a se engajar no corpo burocrático, e o Estado a retomar para si parte de suas atribuições que lhe eram comuns - ao que muitos interpretaram como redução do poder familiar - a família ampliou suas áreas de influência, fenômeno que se percebe, sobretudo no Império, cuja administração recrutava seus membros no interior dos grupos familiares (GRAHAN, 1997).

Ao se analisar, por exemplo, o posto de Delegado de Polícia da cidade de Jaicós, no Piauí, entre as décadas de 1840 e I860, verifica-se a predominância das famílias Sousa Martins, Viera de Carvalho e Araújo Costa entre aqueles que assumiram este cargo. Essas famílias fazem parte do rol de famílias que compuseram a elite colonial piauiense que mantiveram sua hegemonia do poder político por meio de estratégias de mandonismo, entre elas, a indicação de Delegados e Chefes de Polícia.

A importância dessa constatação amplia-se ao se lembrar que os delegados eram os principais agentes dos Presidentes no controle das Províncias. Eles mantinham abertos os canais de comunicação e de reconhecimento da influência e importância dos chefes e famílias locais.

O delegado representava ainda o centro de decisões para o cidadão comum, muitas vezes único agente do Estado com que entrava em contato. O poder local dos delegados originava-se de seu direito do uso da força e armas dos corpos policiais, além do poder de recrutamento das forças policiais, instrumento manejado por estas autoridades locais, em geral homens de posse. Cabe lembrar ainda que durante o recrutamento abria-se a 
possibilidade da gratidão pela dispensa, expediente muito usado por delegados em épocas de eleições.

Os delegados, embora nomeados pelo Governo da Província, por extensão pelo Imperador, provinham em geral da classe dos proprietários rurais membros das redes de poder local. Os titulares desses cargos passaram, assim, a deter autoridade sobre a sina dos mais pobres, instrumento poderoso nas mãos dessas redes familiares.

Destaque-se também que os governantes não podiam prescindir da nomeação das forças policiais, que possuíam como uma de suas missões garantirem a tranquilidade dos pleitos eleitorais e, por sua vez, empenhavam-se com entusiasmo, inclusive na promoção de fraudes.

De maneira geral, o recrutamento era uma prática arbitrária utilizada desde os tempos coloniais, que perdurou pelas primeiras décadas do século XIX. Representou, inclusive, uma das causas mais importantes para a eclosão da Balaiada, um dos movimentos mais violentos do período regencial.

No Piauí, o fenômeno da ampliação das áreas de influência das famílias tornou-se mais visível com o surgimento da vida municipal a partir da segunda metade do século XVIII. Como destaca Brandão, "o prestígio e poder do grupo familiar foram garantidos através do controle do poder do estado, exercido através da ocupação de cargos e funções político-administrativos" (I995, p. 97).

Desde a instalação do governo, os grupos familiares de elite - proprietários de terras, gado e de escravos - organizaram-se de forma a atuar politicamente através das câmaras e demais instâncias burocráticas, observando-se um maior engajamento das famílias por meio de seus membros no aparelho burocrático. Assim, a presença do Estado, se por um lado, enfraqueceu a força dos grupos familiares, reavendo espaços tomados pelas famílias, por outro, ofertou a estes grupos novos espaços de atuação, novas frentes, sobretudo espaços de embates políticos e econômicos, estreitando ainda mais suas redes de poder, que possuíam por amálgama laços a partir do núcleo familiar.

Assim, na Colônia, o mesmo podendo ser dito sobre o Império, a família constituiu-se como forma de um grupo se perpetuar no poder (DEL PRIORE, I999), fortalecendo-se por meio das alianças entre os grupos, formando redes familiares através do casamento, nas quais a união dos cônjuges, mais que a união de pessoas, representava também a união de famílias, pois,

[...] para a elite do Piauí colonial a decisão de constituir família passava pelo desejo e necessidade de gerar filhos continuadores do nome da 
família e herdeiros legítimos do patrimônio privado. Entre as pessoas dessa camada social o casamento apresentava-se ainda, como instrumento de vinculação entre famílias. A prole de um casal era prova concreta desse tipo de união e liame para novas alianças. Adivinha daí a importância do casamento na formação da família de elite piauiense, espinha dorsal da estrutura social e base da estrutura de poder na capitania (BRANDÃO, 1995, p. 139).

No Piauí colonial a família conjugal ganhou especial importância, visto que o casamento, em particular para as famílias da elite, representava ato social com implicações econômicas e políticas, desempenhando destacado papel na sociedade como dispositivo de articulação, cujo sentido era a mediação entre o indivíduo e a sociedade. Dessa forma, o sacramento do casamento para a sociedade representava mais que a união de dois cristãos diante de Deus, era também rito social que marcava ao mesmo tempo a união de famílias, instrumento fundamental na composição das redes familiares.

Apesar das ações da Igreja no sentido de encaminhar a população colonial brasileira ao matrimônio, esta não conseguiu impor a união matrimonial como única forma de relacionamento sexual, apesar da celebração do matrimônio representar objeto de muita atenção, por envolver muitos interesses. Durante a Colônia, muitas uniões podem ser classificadas como consensuais ou clandestinas - ilegítimas pelas leis canônicas e civis do Estado - encontrando alto índice no Piauí, sobretudo se considerar que no Brasil o casamento oficial não se generalizou durante o período colonial (BRANDÃO, 1995).

O casamento oficial encontrou maior espaço apenas entre os grupos de maiores posses, nos quais o mesmo representava, além da união de pessoas, a união de bens e de famílias. No entanto, por meio do sacramento do matrimônio imprimia-se um caráter divino e legal às famílias. O "ser casado" representava uma condição almejada, um "dever ser", símbolo de reconhecimento e respeito social.

A importância da família conjugal ainda se faz sentir pela legitimidade que conferia aos seus herdeiros, "nomeando os controladores do nome da família e herdeiros natos do patrimônio dos pais" (BRANDÃO, 200I, p. I84.). Um patrimônio material que servia de base ao patrimônio político-social da família.

Em face disso, o casamento representava instrumento de manutenção e ampliação do patrimônio privado e para evitar a dispersão dos bens. As gerações mais novas herdavam os bens materiais, prestígio e poder de seus ascendentes com a tarefa de mantê-los e/ou ampliá-los por meio das alianças matrimoniais. 
Nesses casamentos, pouco significado teria o amor entre os nubentes, "seus interesses pessoais em termos de atração física e afetividade eram marginalizados" (BRANDÃO, I995, I48). A escolha do cônjuge deveria atender a critérios, sobretudo políticos e econômicos. Fazia-se, em geral, dentro de um ciclo limitado de sujeitos que atendiam aos padrões e normas determinados. Eram observadas a origem e posição socioeconômica dos candidatos a nubentes e a aquiescência de suas famílias.

Como o número de pessoas de projeção social ${ }^{\mathrm{II}}$ manteve-se sempre reduzido, até o século XIX, o mercado nupcial interno também se apresentou limitado para a elite local. Como a escolha de cônjuge deveria ocorrer entre "iguais", nesse grupo da sociedade piauiense, predominaram os casamentos entre pessoas de um pequeno conjunto de famílias. A partir disso, formaram-se estreitas redes familiares de natureza endogâmica, que predominaram no exercício do controle do poder político no Piauí.

Além do vínculo matrimonial e consanguíneo, essas redes mantinham-se unidas por laços de solidariedade e de dependência material, moral e política que caracterizaram o relacionamento entre seus membros. Assim, o fato de nascer dentro dessas redes familiares representava condição natural que possibilitava inserção em espaços de mando. Competia a esse novo membro ampliar o patrimônio e o prestígio pessoal e familiar. A contínua reprodução dessa ordem familiar gerou o que se pode chamar de uma "elite de primos".

A consolidação dessas famílias como elite ocorreu a partir da instalação da Capitania, quando a população local sofreu reestruturações em face do redirecionamento das concessões de sesmarias, privilegiando os habitantes da região, e do engajamento destes no aparelho administrativo.

Torna-se pertinente também assinalar que, entre os casais troncos das redes familiares no Piauí, nem todos eram constituídos por proprietários de terra, sobretudo os reinóis que na região se estabeleceram. No entanto, "verifica-se que no período entre I762 e I822 as famílias originárias dessas pessoas compunham a elite local. Nesse período, elas, além de adquirirem a condição de proprietários de terra, gado e escravos, conseguiram manter-se hegemônicas no campo político" (BRANDÃO, I995, p. I50).

Na passagem do século XVIII para o XIX, a malha familiar das lideranças políticas no Piauí tornou-se ainda mais extensa e com grande influência em outras partes da Colônia.

\footnotetext{
${ }^{\text {II }} \mathrm{Na}$ sociedade do Piauí oitocentista, representavam pessoas de projeção social os proprietários de bens como terra, gado e escravos, os membros da administração, bem como portugueses que no Piauí se estabeleceram. Durante o século XVIII, formaram-se ali os primeiros grupos familiares. Esses tiveram a seu favor a possibilidade de se estruturar e formar patrimônio constituído de terras, gado e escravos, o que lhes garantiram domínio e prestígio no conjunto da sociedade local no século seguinte.
} 
Compunha-se basicamente de primos, graças a alianças celebradas pelos casamentos consanguíneos e parentes por afinidade.

Desse modo, no Centro-Sul do Piauí formou-se um influente e extenso núcleo familiar, originado a partir do tronco Valério Coelho Rodrigues e Domiciana Vieira de Carvalho, que controlaram a vida política da Província por grande parte do século XIX. Como destaca Tanya Brandão, "nesse conjunto de primos não se pode isolar os Coelho Rodrigues, os Alves da Rocha, os Araújo Costa, os Pereira da Silva, os Santos, os Sousa Martins, os Mendes, os Paiva, os Ferreira Gomes, dentre outros nomes que figuram na genealogia Vieira de Carvalho” (1995, p. 174). Essas famílias compuseram a elite colonial piauiense, na qual "esta rede familiar mantém a hegemonia do poder político e, utilizando estratégias políticas de mandonismo local, garantem tal hegemonia até a República" (BRANDÃO, I995, p. 313).

Por outro lado, ao Norte da Província, formou-se, com já conhecido pela historiografia, outro importante núcleo familiar para a vida sócio-política do Império. Esse núcleo encontra na família Castelo Branco seus principais representantes. Sua origem remonta ao português D. Francisco da Cunha Castelo Branco, Capitão de Infantaria em Portugal, casado com Maria Eugenia de Mesquita e irmão do Conde de Pombeiro, que chegou ao Brasil em I693. Após um tempo no Pernambuco, decide mudar-se para o Maranhão, mas naufraga em sua transferência e decide fixar-se em Santo Antonio de Serubim de Campo Maior. Desse tronco familiar do Norte da Província, originou-se extensa família, que se espalhou por todo o Brasil, e que entrou em choque com interesses do núcleo familiar do Centro-Sul, liderados pelos Sousa Martins.

Segundo Ana Rêgo (200I), entre as famílias que atuaram junto à administração da Província na condição de Presidentes, Vice-Presidentes e de deputados provinciais, destacam-se as famílias Vieira de Carvalho, Coelho Rodrigues, Sousa Martins, Pereira da Silva, Ferreira de Carvalho, Coelho, Sousa Mendes e Araújo Costa.

Essas famílias compunham uma rede de famílias do Centro-Sul piauiense que tiveram forte influência sobre a administração provincial, influência que se estende à República. Sua influência sobre a administração provincial pode ser observada por meio das cadeiras ocupadas por seus representantes na Assembleia Provincial no período imperial, no qual, por exemplo, durante a Regência, observa-se uma confortável posição no legislativo provincial, liderados pelos Sousa Martins e aparentados. Dentre os 39 deputados que assumiram suas funções à Assembleia Provincial para as legislaturas de I835/7 e I838/9, 22 deputados $(56,4 \mathrm{I} \%)$ guardavam afinidade com o núcleo familiar do Centro-Sul, ao instante que apenas seis deputados ( $15,38 \%)$ vinculam-se ao núcleo familiar do Norte, 
representados pela família Castelo Branco e aparentados. Apesar de não ser possível precisar a vinculação política ou familiar de II dos deputados $(28,2 \%)$ - alguns por não serem de famílias piauienses - é certo que se vincularam a um dos dois núcleos familiares sem, no entanto, modificar a hegemonia do núcleo do Centro-Sul.

Entre os anos de I840 e I852, período de organização do II Império, dos 70 eleitos, 31 deputados (44\%) vinculavam-se ao núcleo Centro-Sul, II deputados (I6\%) ao núcleo Norte e 28 deputados (40\%) não possuíam vínculos familiares diretos a nenhum dos dois grupos, mas, possivelmente ligaram-se a um dos dois. Para o período de I852 a I870, período de apogeu do reinado de D. Pedro II, a relação de força entre as famílias pouco se alterou. Dos I23 cargos de deputados, 5 I destes (42\%) ligavam-se ao núcleo do Centro-Sul, 25 (2I\%) ligavam-se ao núcleo Norte e 47 deputados (37\%) não possuíam ligações familiares diretas com nenhum dos dois grupos.

Para o último período do II Império, entre os anos de I870 e I889, assiste-se a um enfraquecimento no Núcleo Centro-Sul, mas que ainda mantinha-se forte. Das 243 cadeiras, $24 \%$ dos deputados vinculavam-se ao núcleo Centro-Sul, I4\% ao núcleo Norte. $62 \%$ dos deputados não se vinculavam diretamente a nenhum dos grupos, entretanto, aliavam-se a um ou outro grupo (RÊGO, 200I).

A representatividade política das famílias do Centro-Sul pode ainda ser observada por meio da origem familiar dos vice-presidentes da Província que assumiram interinamente a Presidência durante o Império. Dos 27 vice-presidentes que assumiram interinamente a presidência, nove $(33,4 \%)$ pertenciam ao núcleo familiar do Centro-Sul, quatro $(14,8) \%$ vinculavam-se ao núcleo Norte e I4 $(51,9 \%)$, alguns oriundos de outras províncias, não possuíam vinculação familiar direta a nenhum dos dois núcleos.

\section{Considerações finais}

A relação entre família e poder representou uma constante no processo de formação da sociedade piauiense, na qual a constituição dos grupos dirigentes se deu pela utilização de mecanismos que propiciaram a seus membros legitimarem e ampliarem seu prestígio e poder por meio da aquisição da propriedade rural e da ocupação de cargos e de funções no aparelho burocrático do Estado. Esses mecanismos foram responsáveis pela conquista e manutenção da primazia política durante a formação da sociedade colonial piauiense BRANDÃO, 1995, p. 312).

A forte presença de representantes de núcleos familiares específicos na administração pública sinaliza para a importância das famílias na organização do poder 
local, entre as quais, sobressaem-se, para os objetivos deste escrito, a rede familiar do Centro-Sul, na qual os Sousa Martins foram seus principais representantes, e a rede familiar do Norte da Província, dentre as quais os membros da família Castelo Branco foram seus principais representantes.

Deve-se destacar mais uma vez que, no Piauí, a propriedade rural firmou-se desde cedo como um dos elementos definidores dos grupos dominantes, tendo como elemento de unificação o vínculo familiar. Os laços de parentesco deram forma a extensos grupos familiares, cuja força política se fazia sentir, para além de suas propriedades. Detinham o poder na Província, face ao controle político exercido por membros dessas famílias, engajados na administração pública. Dessa forma, integrar uma família de poder e prestígio local significava também transitar por espaços de comando ou dos quais se poderiam obter maiores oportunidades de multiplicar tal prestígio.

\section{Referências Bibliográficas}

ABREU, Capistrano de. Capítulos de história colonial. 6. ed. Rio de Janeiro: Civilização Brasileira, 1976. ALENCASTRE, José Martins Pereira de. Memória cronológica, histórica e corográfica da província do Piauí. Teresina: SEDUC, 2005.

ALENCASTRO, Luiz Felipe. Modelos da História e da historiografia imperial. In: NOVAIS, Fernando A. História da vida privada no Brasil: Império. São Paulo: Companhia das Letras, 1997.

ARAÚJO COSTA, Sebastião Martins de; ROCHA, Moacyr Sipaúba da; REZENDE, José Ferreira de Sousa. Dados genealógicos da família Rocha. 3. ed. rev. e ampli. Teresina, 1999.

BRANDÃO, Tanya Maria Pires. A elite colonial piauiense: família e poder. Teresina: Fundação Monsenhor Chaves, 1995.

BRANDÃO, Tanya Maria Pires. A religiosidade no Piauí colonial: catolicismo adaptado ao modo de vida. In: CLIO. Revista de Pesquisa Histórica. Recife: Editora Universitária da UFPE, n. 22, 2006.

BRANDÃO, Tanya Maria Pires. Antigas lutas, novos cenários: a elite piauiense e a independência. In: CLIO. Revista de pesquisa histórica. n. 20, 2002. Recife. Universidade Federal de Pernambuco. Programa de pós-graduação em história. Centro de filosofia e ciências humanas. Recife: Universitária da UFPE, 2004.

BRANDÃO, Tanya Maria Pires. Matrimônio: legalidade e sagração da família no Piauí colonial. In: SILVA, Maria Beatriz Nizza. Sexualidade, família e religião na colonização do Brasil. Lisboa: livros horizonte, 200I.

BRANDÃO, Tanya Maria Pires. O escravo na formação social do Piauí: perspectiva histórica do século XVIII. Teresina: Editora da Universidade Federal do Piauí, I999. 
CARDOSO, Ciro Flamarion Santana. O trabalho na Colônia. In: LINHARES, Maria Yeda (Org.). História geral do Brasil. 9. ed. Rio de Janeiro: Campus, 1996.

CARVALHO, Abimael Clementino de. Família Coelho Rodrigues: passado e presente. Fortaleza: Imprensa oficial do Ceará, 1988.

CASTELLO BRANCO FILHO, Moysés. A família rural do Piauí. Teresina; Companhia Editora do Piauí, 1983.

CASTELLO BRANCO FILHO, Moysés. O povoamento do Piauí. Rio de Janeiro: Cia Brasileira de Artes Gráficas, 1982.

CASTELO BRANCO, Pedro Vilarinho. Famílias e escritas: a prática discursiva dos literatos e as relações familiares em Teresina nas primeiras décadas do século XX. Tese apresentada ao Programa de Pós-graduação em História da UFPE. Recife, 2005.

CASTELO BRANCO, Pedro Vilarinho. Mulheres plurais: a condição feminina em Teresina na Primeira República. Teresina: F.C.M.C., 1996.

CHAVES, Joaquim Raimundo Ferreira. Obra completa. Prefácio de Teresinha Queiroz - Teresina: Fundação Cultural Mons. Chaves, 1998.

COSTA, Francisco Augusto Pereira da. Cronologia histórica do estado do Piauí. Rio de Janeiro: Artenova, vol. I e II, 1974 .

DEL PRIORE, Mary. A família no Brasil colonial. São Paulo: Moderna, 1999.

GRAHAN, Richard. Clientelismo e política no Brasil do século XIX. Rio de Janeiro: Editora UFRJ, I997.

KUZNESOF, Elizabeth. A família na sociedade brasileira: parentesco, clientelismo e estrutura social (São Paulo). Revista Brasileira de História, São Paulo, n. 9, 1988/89.

LEWIN, Linda. Política e parentela na Paraíba: um estudo de caso da oligarquia de base familiar. Tradução André Villalobos. Rio de Janeiro: Record, 1993.

MARIANO, Serioja Rodrigues Cordeiro. Gente opulenta e de boa linhagem: família, política e relações de poder na Paraíba. Tese apresentada ao Programa de Pós-Graduação em História da UFPE. Recife, 2005.

NEVES, Abdias. A guerra do Fidié. 2. ed. Rio de Janeiro: Artenova, 1974.

NEVES, Abdias. O Piauí na confederação do Equador. Teresina: Ed. EDUFPI, 1997.

NOVAIS, Fernando A. Condições da privacidade na colônia. In: SOUZA, Laura de Mello e. História da vida privada no Brasil: cotidiano e vida privada na América portuguesa. São Paulo: Cia das Letras, 1997.

NUNES, Odilon. Pesquisas para a história do Piauí. Rio de Janeiro: Artenova, vol. I, II, III e IV, I975.

PINTO, Luiz de Aguiar Costa. Lutas de família no Brasil: introdução ao seu estudo. 2. ed. São Paulo: Editora Nacional, 1980.

RÊGO, Ana Regina Barros Leal. Imprensa piauiense: atuação política no século XIX. - Teresina: Fundação Cultural Monsenhor Chaves, 200I.

SANTANA, Raimundo Nonato Monteiro. Piauí: formação - desenvolvimento - perspectivas. Teresina: Harley, 1995; 
SILVA, Maria Beatriz Nizza da. História da Família no Brasil colonial. Rio de Janeiro: Nova Fronteira, 1998.

SOUSA, Esmaragdo de Freitas. O Visconde da Parnaíba. Rio de Janeiro: Ed. Jornal do Comércio, I947. SOUSA NETO, Marcelo de. Entre Vaqueiros e Fidalgos: sociedade, política e educação no Piauí do século XIX. Teresina: Fundação Monsenhor Chaves, 2013.

TITO FILHO, José de Arimatéia. Esmaragdo de Freitas, homens e episódios. Teresina: COMEPI, 1973. 